\title{
EFFECT OF WORKBENCH SHIELDING ON NAGASAKI FACTORY WORKERS' DOSE
}

\author{
Y. Y. Azmy \\ R. T. Santoro \\ D. B. Simpson \\ J. V. Pace III
}




\section{DOCUMENT AVAILABILITY}

Reports produced after January 1, 1996, are generally available free via the U.S. Department of Energy (DOE) Information Bridge.

Web site http://www.osti.gov/bridge

Reports produced before January 1, 1996, may be purchased by members of the public from the following source.

National Technical Information Service

5285 Port Royal Road

Springfield, VA 22161

Telephone 703-605-6000 (1-800-553-6847)

TDD 703-487-4639

Fax 703-605-6900

E-mail info@ntis.fedworld.gov

Web site http://www.ntis.gov/support/ordernowabout.htm

Reports are available to DOE employees, DOE contractors, Energy Technology Data Exchange (ETDE) representatives, and International Nuclear Information System (INIS)

representatives from the following source.

Office of Scientific and Technical Information

P.O. Box 62

Oak Ridge, TN 37831

Telephone 865-576-8401

Fax 865-576-5728

E-mail reports@adonis.osti.gov

Web site http://www.osti.gov/contact.html

This report was prepared as an account of work sponsored by an agency of the United States Government. Neither the United States Government nor any agency thereof, nor any of their employees, makes any warranty, express or implied, or assumes any legal liability or responsibility for the accuracy, completeness, or usefulness of any information, apparatus, product, or process disclosed, or represents that its use would not infringe privately owned rights. Reference herein to any specific commercial product, process, or service by trade name, trademark, manufacturer, or otherwise, does not necessarily constitute or imply its endorsement, recommendation, or favoring by the United States Government or any agency thereof. The views and opinions of authors expressed herein do not necessarily state or reflect those of the United States Government or any agency thereof. 


\title{
EFFECT OF WORKBENCH SHIELDING ON NAGASAKI FACTORY WORKERS' DOSE
}

\author{
Y. Y. Azmy \\ R. T. Santoro \\ D. B. Simpson \\ J. V. Pace III \\ Computational Physics and Engineering
}

Date published: March 2001

Prepared by the

OAK RIDGE NATIONAL LABORATORY

Oak Ridge, TN 37831-6363

Managed by

UT-BATTELLE, LLC,

for the

U.S. DEPARTMENT OF ENERGY

under contract DE-AC05-00OR22725 



\section{CONTENTS}

Page

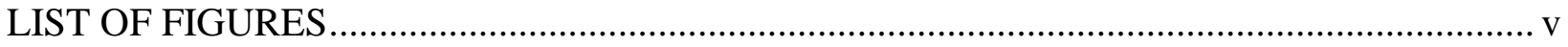

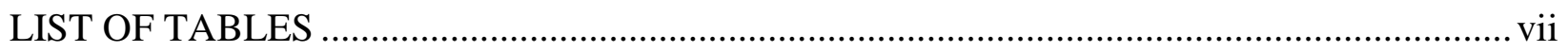

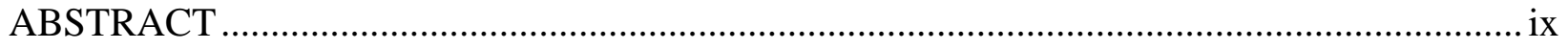

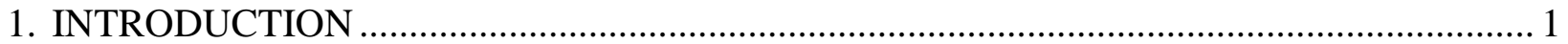

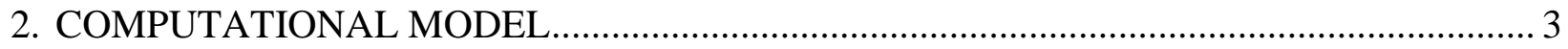

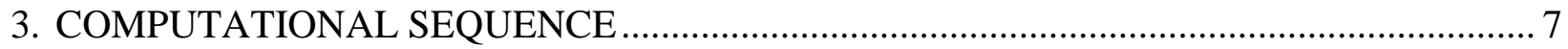

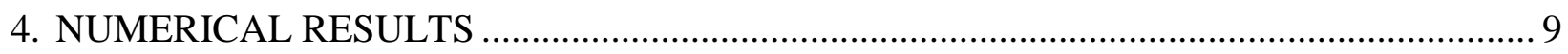

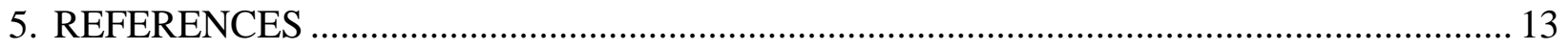

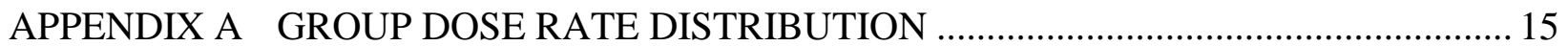





\section{LIST OF FIGURES}

Figure

Page

1. Geometric Configuration, Dimensions and Mesh, for the $r-z$ Model ............................ 4

2. Total Uncollided Plus Collided Neutron, Gamma, and Total Dose Maps Over Entire Domain 10

3. Total Uncollided Plus Collided Neutron, Gamma, and Total Dose Maps Inside Building 11

4. Relative Dose Inside Factory Building With Respect to the Dose Immediately Outside the Wall 12

A1. Neutron Uncollided Plus Collided Dose Maps for Energy Groups 2-7 ......................... 18

A2. Neutron Uncollided Plus Collided Dose Maps for Energy Groups 8-13 ...................... 19

A3. Neutron Uncollided Plus Collided Dose Maps for Energy Groups 14-19..................... 20

A4. Neutron Uncollided Plus Collided Dose Maps for Energy Groups 20-25 ..................... 21

A5. Neutron Uncollided Plus Collided Dose Maps for Energy Groups 26-31 ..................... 22

A6. Neutron Uncollided Plus Collided Dose Maps for Energy Groups 32-37 ..................... 23

A7. Neutron Uncollided Plus Collided Dose Maps for Energy Groups 38-43 ...................... 24

A8. Neutron Uncollided Plus Collided Dose Maps for Energy Groups 44-46..................... 25

A9. Gamma Uncollided Plus Collided Dose Maps for Energy Groups 47-52 ..................... 26

A10. Gamma Uncollided Plus Collided Dose Maps for Energy Groups 53-58 ..................... 27

A11. Gamma Uncollided Plus Collided Dose Maps for Energy Groups 59-64 ..................... 28

A12. Gamma Uncollided Plus Collided Dose Maps for Energy Groups 65-69 ......................29 



\section{LIST OF TABLES}

Table

Page

1. Atom Densities for Nuclides in Seven Regions of Air .................................................. 3

2. Atom Densities for Nuclides in Natural Iron .................................................................. 3

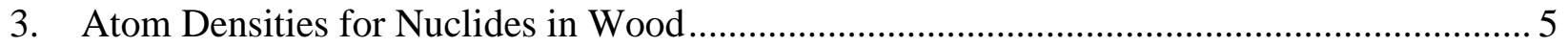

4. Atom Densities for Nuclides in Carbon Steel ................................................................... 5

5. Atom Densities for Nuclides in Wall Material .............................................................. 5

6. Atom Densities for Nuclides in Soil ............................................................................. 5 



\begin{abstract}
Observed discrepancies on the order of $40 \%$ between the previously computed radiation doses to factory workers in a Nagasaki factory and measured values estimated from genetic aberrations are investigated. A conjecture that these discrepancies can be resolved by including the shielding of workers by workbenches and tools is tested. A simple two-dimensional $r-z$ model of the Nagasaki bomb explosion surrounding area with cylindrical shell representations of the factory walls and a smeared workbench is used to set an upper bound on the dose reduction as a function of workbench material. The model covers a $1353.5 \mathrm{~m} \times 1500 \mathrm{~m}$ region, mostly air, discretized by almost 71,000 computational cells; energy is discretized by 46 neutron and 23 gamma groups. Angular anisotropy of scattering is represented by a $\mathrm{P}_{5}$ expansion, while the angular dependence of the angular flux is discretized along a 240 -angle, biased quadrature set. A first collision source is computed by GRTUNCL and used in DORT to compute the fully collided flux in 64-bit arithmetic precision. All groups are converged in DORT to $10^{-4}$, and the sum of the converged flux and GRTUNCL's uncollided flux are folded with flux-to-dose conversion factors to generate pointwise maps of group dose rates. It is concluded that with this simplified model of the workbench, a workbench consisting of only $0.16 \mathrm{~m}$ of solid wood and $0.04 \mathrm{~m}$ of solid carbon steel is sufficient to reduce the total dose by $40 \%$. These are reasonable material contents in a typical workbench, thus the conjecture is affirmed, and more detailed calculations of the total dose to individual workers in various exposure scenarios are expected to eliminate remaining discrepancies.
\end{abstract}





\section{INTRODUCTION}

Radiation doses resulting from the nuclear weapons exploded in Hiroshima and Nagasaki at the conclusion of World War II have long been computed.[1] Several attempts at this daunting task have achieved much progress, but lingering discrepancies between the computed dose and observed radiation effects of various kinds still await resolution. One of these discrepancies is the apparent lower level of exposure to workers in a torpedo factory at Nagasaki as determined from genetic aberrations. We propose that this difference of roughly $40 \%$ can be accounted for by shielding effects from the workbenches and tools.

In this document we report our verification of this hypothesis in a simplified two-dimensional setting using the renowned neutral particle transport code DORT,[2] and companion codes in the Discrete Ordinates Oak Ridge System (DOORS) package.[3] The conclusion of this preliminary investigation is that realistic models of the workbench and tools can indeed result in a $40 \%$ reduction in the dose rate, thus justifying further, more comprehensive modeling of individual workers and their surroundings.

The remainder of this report is organized as follows. We describe the simplified model used in this study in Sec. 2 and delineate the verification exercise. In Sec. 3 we present the computational sequence employed in the calculation, with special attention to difficulties encountered and how they were resolved. Finally, we report the computational results in Sec. 4 and interpret their coincidence with our hypothesis. 



\section{COMPUTATIONAL MODEL}

The basic question addressed in this work is whether a reasonable configuration of the workbench and tools inside a factory building can reduce the dose rate by about $40 \%$. Hence we reduced the geometric representation of the problem domain to the simplest level that permits testing of this hypothesis. The problem domain is comprised of an $r$ - $z$ region extending 1353.5 $\mathrm{m}$ in the radial direction and $1500 \mathrm{~m}$ along the axis of symmetry above ground level, and $0.5 \mathrm{~m}$ below ground level to account for ground shine effects. The weapon explosion is represented by a fixed source with the bomb's spectrum located on the $z$-axis, $500 \mathrm{~m}$ above ground level. The factory and workbench are modeled as cylindrical shells located towards the outer fringe of the problem domain so that the dose reduction computed by this model can be viewed as an upper bound on the expected reduction with the full model. The geometric configuration of the computational model is depicted in Figure 1. We used the two-dimensional neutral particle transport code DORT to solve this problem on a $135 \times 525$ mesh as shown in Figure 1.

Earlier calculations illustrated the small shielding effect of the building roof. Hence, for the purposes of this preliminary study we chose to ignore the roof in modeling the building as in Figure 1.

A new set of cross-section data, created specifically for this problem,[4] possesses the same group structure, 46 neutron, and 23 gamma groups, as the DABL69 library.[5] However, while DABL69 is based on VITAMIN-E data,[6] the new library employs VITAMIN-B6 data[7,8] for all nuclides involved in this problem with one exception. Since Ar data is not available in the VITAMIN-B6 library, we used the Ar cross sections that were in DABL69. The material compositions for all regions depicted in Figure 1 are shown in Tables 1-6.

Table 1. Atom Densities for Nuclides in Seven Regions of Air

\begin{tabular}{|l|l|l|l|l|}
\hline \multirow{2}{*}{} & \multicolumn{4}{|c|}{ Nuclide Density $\left(\mathrm{b}^{-1} \cdot \mathrm{cm}^{-1}\right)$} \\
\cline { 2 - 5 } & \multicolumn{1}{|c|}{${ }^{1} \mathrm{H}$} & \multicolumn{1}{|c|}{$\mathrm{N}$} & ${ }^{16} \mathrm{O}$ & $\mathrm{Ar}$ \\
\hline Air 1 & $1.311 \times 10^{-6}$ & $3.676 \times 10^{-5}$ & $1.052 \times 10^{-5}$ & $2.198 \times 10^{-7}$ \\
\hline Air 2 & $1.231 \times 10^{-6}$ & $3.638 \times 10^{-5}$ & $1.037 \times 10^{-5}$ & $2.176 \times 10^{-7}$ \\
\hline Air 3 & $1.142 \times 10^{-6}$ & $3.593 \times 10^{-5}$ & $1.021 \times 10^{-5}$ & $2.149 \times 10^{-7}$ \\
\hline Air 4 & $1.050 \times 10^{-6}$ & $3.543 \times 10^{-5}$ & $1.003 \times 10^{-5}$ & $2.119 \times 10^{-7}$ \\
\hline Air 5 & $9.590 \times 10^{-7}$ & $3.490 \times 10^{-5}$ & $9.841 \times 10^{-6}$ & $2.087 \times 10^{-7}$ \\
\hline Air 6 & $8.589 \times 10^{-7}$ & $3.426 \times 10^{-5}$ & $9.621 \times 10^{-6}$ & $2.049 \times 10^{-7}$ \\
\hline Air 7 & $7.303 \times 10^{-7}$ & $3.335 \times 10^{-5}$ & $9.312 \times 10^{-6}$ & $1.995 \times 10^{-7}$ \\
\hline
\end{tabular}

Table 2. Atom Densities for Nuclides in Natural Iron

\begin{tabular}{|l|c|c|c|c|}
\hline Nuclide & ${ }^{54} \mathrm{Fe}$ & ${ }^{56} \mathrm{Fe}$ & ${ }^{57} \mathrm{Fe}$ & ${ }^{58} \mathrm{Fe}$ \\
\hline $\mathrm{b}^{-1} \cdot \mathrm{cm}^{-1}$ & $5.011 \times 10^{-3}$ & $7.790 \times 10^{-2}$ & $1.784 \times 10^{-3}$ & $2.378 \times 10^{-4}$ \\
\hline
\end{tabular}




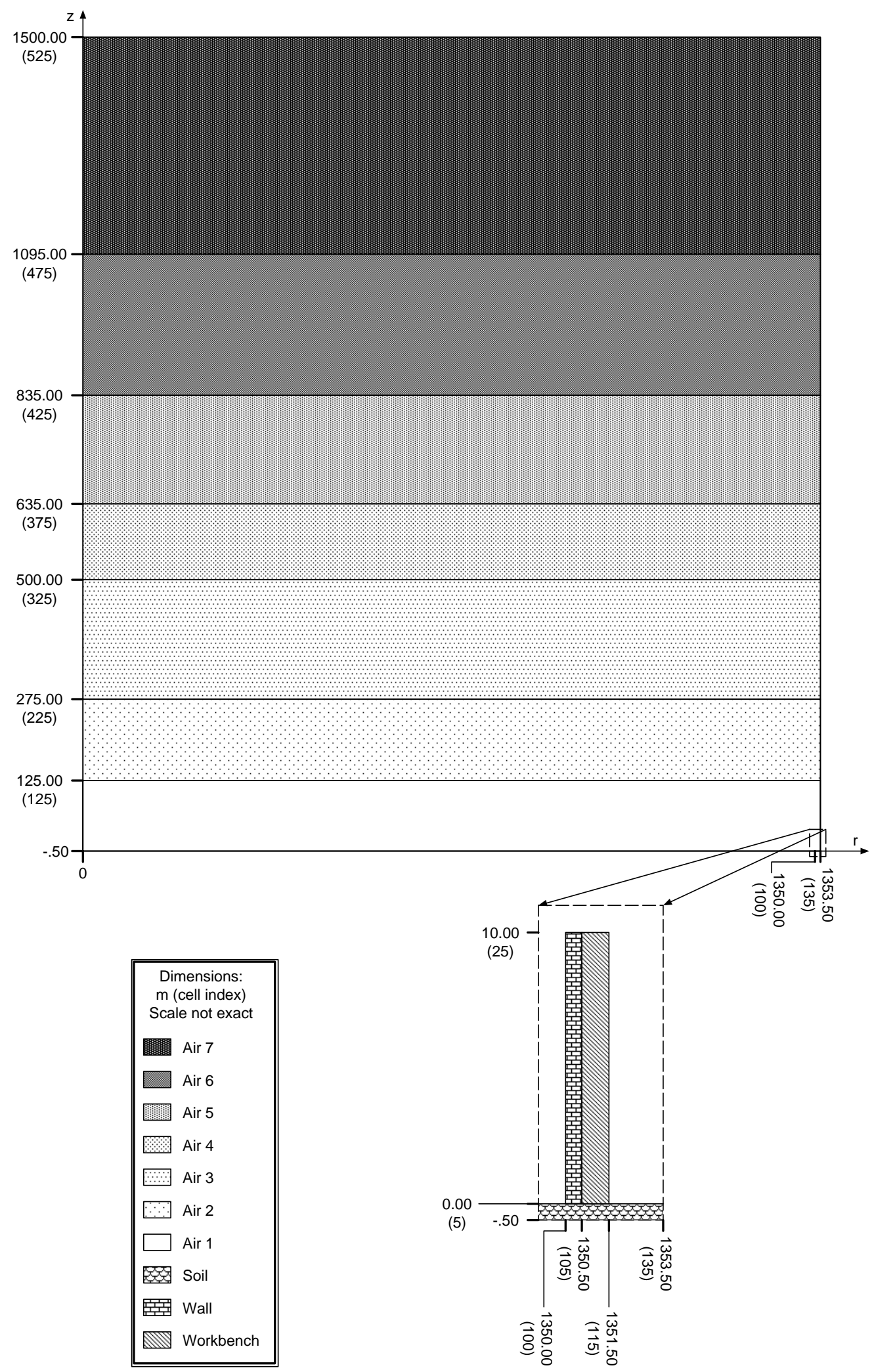

Figure 1. Geometric Configuration, Dimensions and Mesh, for the $r-z$ Model 
Table 3. Atom Densities for Nuclides in Wood

\begin{tabular}{|l|c|c|c|c|}
\hline Nuclide & ${ }^{1} \mathrm{H}$ & $\mathrm{C}$ & ${ }^{14} \mathrm{~N}$ & ${ }^{16} \mathrm{O}$ \\
\hline $\mathrm{b}^{-1} \cdot \mathrm{cm}^{-1}$ & $4.050 \times 10^{-2}$ & $2.131 \times 10^{-2}$ & $3.655 \times 10^{-4}$ & $1.878 \times 10^{-2}$ \\
\hline
\end{tabular}

Table 4. Atom Densities for Nuclides in Carbon Steel

\begin{tabular}{|l|c|c|c|c|}
\hline Nuclide & $\mathrm{C}$ & $\mathrm{Si}$ & ${ }^{55} \mathrm{Mn}$ & Iron \\
\hline $\mathrm{b}^{-1} \cdot \mathrm{cm}^{-1}$ & $7.883 \times 10^{-4}$ & $4.214 \times 10^{-4}$ & $3.878 \times 10^{-4}$ & $8.401 \times 10^{-2}$ \\
\hline
\end{tabular}

Table 5. Atom Densities for Nuclides in Wall Material

\begin{tabular}{|c|c|c|c|c|}
\hline Nuclide & $\mathrm{Mg}$ & $\mathrm{Si}$ & ${ }^{16} \mathrm{O}$ & ${ }^{1} \mathrm{H}$ \\
\hline $\mathrm{b}^{-1} \cdot \mathrm{cm}^{-1}$ & $3.394 \times 10^{-3}$ & $6.203 \times 10^{-3}$ & $4.323 \times 10^{-2}$ & $3.313 \times 10^{-3}$ \\
\hline \hline Nuclide & ${ }^{27} \mathrm{Al}$ & Iron & $\mathrm{Ca}$ & \multirow{2}{*}{} \\
\cline { 1 - 4 } $\mathrm{b}^{-1} \cdot \mathrm{cm}^{-1}$ & $3.189 \times 10^{-3}$ & $1.344 \times 10^{-3}$ & $1.897 \times 10^{-2}$ & \\
\cline { 1 - 3 }
\end{tabular}

Table 6. Atom Densities for Nuclides in Soil

\begin{tabular}{|c|c|c|c|c|}
\hline Nuclide & ${ }^{1} \mathrm{H}$ & $\mathrm{C}$ & ${ }^{16} \mathrm{O}$ & ${ }^{23} \mathrm{Na}$ \\
\hline $\mathrm{b}^{-1} \cdot \mathrm{cm}^{-1}$ & $3.521 \times 10^{-2}$ & $1.806 \times 10^{-3}$ & $3.857 \times 10^{-2}$ & $2.556 \times 10^{-4}$ \\
\hline Nuclide & ${ }^{27} \mathrm{Al}$ & $\mathrm{Si}$ & $\mathrm{Cl}$ & $\mathrm{K}$ \\
\hline $\mathrm{b}^{-1} \cdot \mathrm{cm}^{-1}$ & $2.816 \times 10^{-3}$ & $6.806 \times 10^{-3}$ & $7.512 \times 10^{-6}$ & $1.510 \times 10^{-4}$ \\
\hline Nuclide & $\mathrm{Ca}$ & $\mathrm{Ti}$ & ${ }^{55} \mathrm{Mn}$ & Iron \\
\hline $\mathrm{b}^{-1} \cdot \mathrm{cm}^{-1}$ & $2.267 \times 10^{-4}$ & $1.034 \times 10^{-4}$ & $1.796 \times 10^{-5}$ & $8.247 \times 10^{-4}$ \\
\hline
\end{tabular}

Note that the iron entry in Tables 4-6 is not a nuclide, but rather a natural mixture of Fe nuclides in the proportions shown in Table 2. The external wall of the factory building is represented by a mixture of $95 \%$ wall material and 5\% carbon steel by volume. This ratio was estimated by visual inspection of the typical torpedo factory building walls. Also, to account for the thick cells assigned to the wall in the computational model, $0.1 \mathrm{~m}$, we used a density factor of $20 \%$ to dilute the mixed material density in these cells. The results presented below suggest a smaller attenuation of the dose inside the wall than earlier calculations indicated, which leads us to suspect that we underestimated the content of the iron in the wall composition. While this inaccuracy must be avoided in the final model and calculations, we conjecture that it has no significant effect on the present investigation because what we seek here is a relative drop in 
dose, not the value of the dose itself. Hence, spectral effects from additional shielding by the iron might influence the dose reduction but not substantially to alter the proof of principle conclusion. The workbench is represented by a mixture of wood and carbon steel in the ratio $80 \%$ and $20 \%$, by volume, respectively. This ratio is deemed a reasonable representative configuration of a generic factory workbench that is diluted by a density factor of $50 \%$ to account for the thickness of the computational cells in that region.

Accuracy of a neutral particle transport calculation like the one at hand depends significantly on the accuracy of the representation of the angular dependence. The large air content and the point nature of the source, in relative dimensions, ensure the existence of strong ray effects as our early calculations illustrated. Even with a first-collision source generated via a GRTUNCL[9] run as described below, ray effects still persisted in some of the gamma groups. This behavior was observed in earlier calculations, and a 240-angle biased angular quadrature was created to deal adequately with ray effects. Also, we employed a $\mathrm{P}_{5}$ representation of anisotropic scattering. The resulting flux and dose profiles exhibit no abnormalities characteristic of ray effects, raising our confidence in the accuracy of the angular discretization used. 


\section{COMPUTATIONAL SEQUENCE}

Early experiments with this problem illustrated the grave importance of arithmetic precision, especially with regard to the success of iterative acceleration and convergence. The numerical results presented in the following section have been obtained using ORNL's Compaq AlphaServer running the Tru64 version 5.0 operating system with 64-bit arithmetic precision. Due to limited resources, a complete installation of the DOORS package in 64-bit environment was not performed. Instead, we installed the three member codes necessary for this computation, namely, GIP,[10] GRTUNCL, and DORT.

First, the cross-section data from the new library were written in ASCII format and combined with the DABL69 data for Ar. The combined set was transferred to the AlphaServer, and GIP was executed to generate the binary cross-section file in 64-bit precision.

Next, GRTUNCL was executed on the model described above with the Nagasaki bomb spectrum[4] specified as a unit-normalized source $500 \mathrm{~m}$ above ground level on the $z$-axis. Note that the normalization is to one source particle over all neutron and gamma groups. Again, this is an approximation that is adequate since the preliminary nature of the present study focused on the relative change in dose. GRTUNCL writes out an unformatted file, containing the uncollided flux and the first collision source.

An input parameter to DORT, namely $n t f c i$, flags the code that this calculation is based on a firstcollision source. In this case, DORT reads the group source by cell from the unformatted file produced by GRTUNCL, and uses it to perform the inner iterations for each group to compute the fully collided flux. Upon termination of all iterations, DORT automatically sums the uncollided flux on GRTUNCL's unformatted output file to the fully collided flux computed in the last inner iteration.

Transport calculations are notorious for having difficulty converging, especially in deep penetration cases with a high degree of anisotropy. Experimentation with some parameters with a simplified model in advance of production runs is usually instructive and can result in great saving in time and effort later. Among the special settings that we found necessary to solve this problem successfully are the following:

1. Setting the negative flux fixup to economy rather than full, saves execution time and allows for better convergence of the inner iterations.

2. Partial Current Rebalance acceleration is more robust for most groups than Diffusion Synthetic Acceleration.

3. Setting the minimum flux value tested for convergence to $10^{-30}$, rather than the default $10^{-60}$, since flux values this small do not influence the computed dose. 
4. Setting the minimum number of acceleration iterations to 0 instead of the default 4 avoids instances where the mesh sweep and acceleration work against one another resulting in unnecessary lack of convergence in affected groups.

The high arithmetic precision employed in these calculations encouraged us to converge the flux to a pointwise relative criterion of $10^{-4}$ rather than the typical $10^{-3}$. All groups converged to this strict criterion in 15 or fewer inner iterations, except for group 46, thermal neutrons, which converged in 221 inner iterations. DORT's unformatted flux output file is structured to hold all computed angular moments of the flux. In the present case, DORT sums the fully collided flux, as computed in the last iteration performed, with the uncollided flux resulting from the GRTUNCL step of the calculation. Since GRTUNCL does not save higher angular moments of the flux, DORT's flux output file contains the total flux only in the scalar-flux locations, and the fully collided flux in all higher angular moments locations. Only the scalar flux is needed for computing dose rates; hence a simple code was implemented to read this file and print out only the scalar flux in ASCII format for portability purposes. The latter was then transferred to one of the 32-bit machines on which the graphics package, ISOPLOT, is operational.

Group dose-rate (proportional to each group scalar flux) color coded maps over the entire problem domain that have been generated by ISOPLOT are shown in the Appendix. Since the bomb spectrum is zero in group 1 and no upscattering is considered, the flux map (all zero) for this group is not shown. It is evident from these plots that the high-order quadrature employed is quite successful in reducing secondary ray effects even if some remain in most groups, manifested as fine, saw-tooth like structures on contour lines. It is worth noting that earlier experiments in which we used an $S_{6}$ quadrature to compute the fully collided flux exhibited extremely strong ray effects, particularly in the gamma groups, even in conjunction with a GRTUNCL run. 


\section{NUMERICAL RESULTS}

The group flux computed by GRTUNCL and DORT is finally folded with the flux to free-in-air dose conversion factor, and the resulting neutron, gamma, and total dose rates are plotted as color coded maps in Figure 2. Consistent with earlier observations, the total dose over most of the problem domain is dominated by gammas. Secondary ray effects are evident in the summed doses, but they are small compared to other sources of uncertainty in the calculation. In general, the plots exhibit reasonable behavior: concentric spherical shapes centered at the bomb explosion point with the dose decreasing along the radial direction.

The scale of the plots in Figure 2 does not show the behavior of the dose inside the factory building. Hence, we zoom on this region for the neutron, gamma, and total dose rates in Figure 3. Again, no surprises are exhibited in the dose rate behavior presented in these plots.

In order to verify our hypothesis, we examine the neutron, gamma, and total dose inside the factory building as a function of the radial distance from ground zero, $r$. Since we are interested in relative drop in the dose rate due to shielding by the workbench, in Figure 4 we plot the dose rate $v s r$ relative to its value in the air immediately outside the wall. The dose profile does not change significantly with height above the ground, as evident from Figure 3, so even though Figure 4 is specifically based on values at $0.25 \mathrm{~m}$ it is well representative of the dose drop up to $1.75 \mathrm{~m}$ above ground level. As noted earlier, the low iron content in the wall causes the dose rate to drop very little across the first $0.5 \mathrm{~m}$ in Figure 4, then the dose drops by about $40 \% 0.4 \mathrm{~m}$ deep into the workbench. Given the material density applied to the workbench, as described in Section 2, this amounts to about $0.16 \mathrm{~m}$ of solid wood, and $0.04 \mathrm{~m}$ of solid carbon steel to reduce the total dose by $40 \%$. Clearly this is reasonable compared to the typical dimensions of a workbench and tools on it, thus verifying our hypothesis that ignoring the shielding effect of the workbenches in earlier models could have resulted in an underestimate in the dose rate consistent with discrepancies observed in genetic aberrations. 


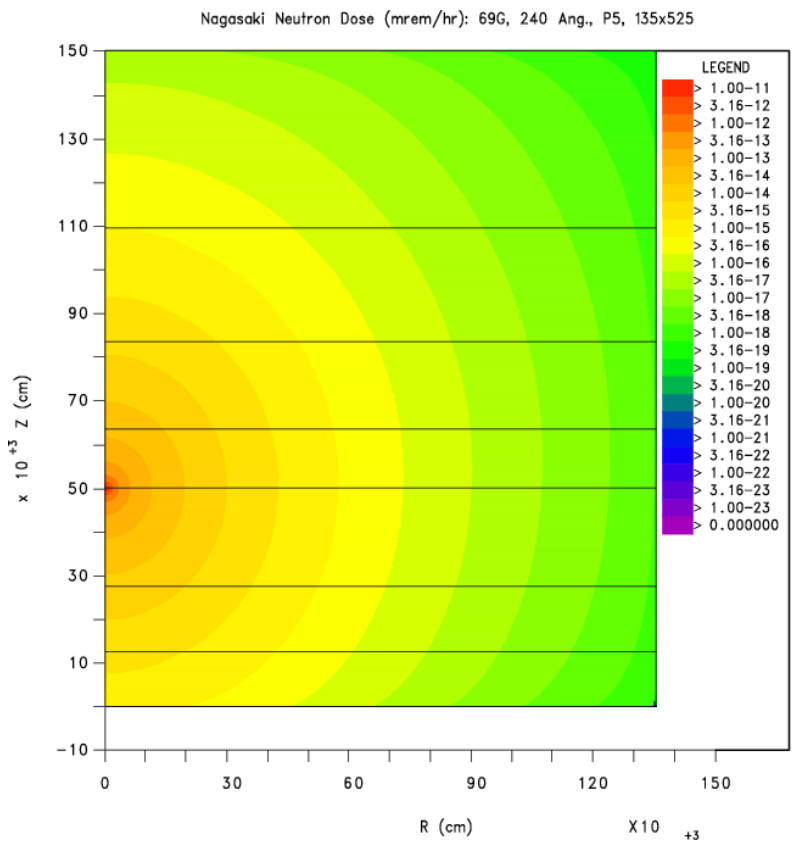

Nagasaki Gamma Dose (mrem/hr): 69G, 240 Ang., P5, $135 \times 525$
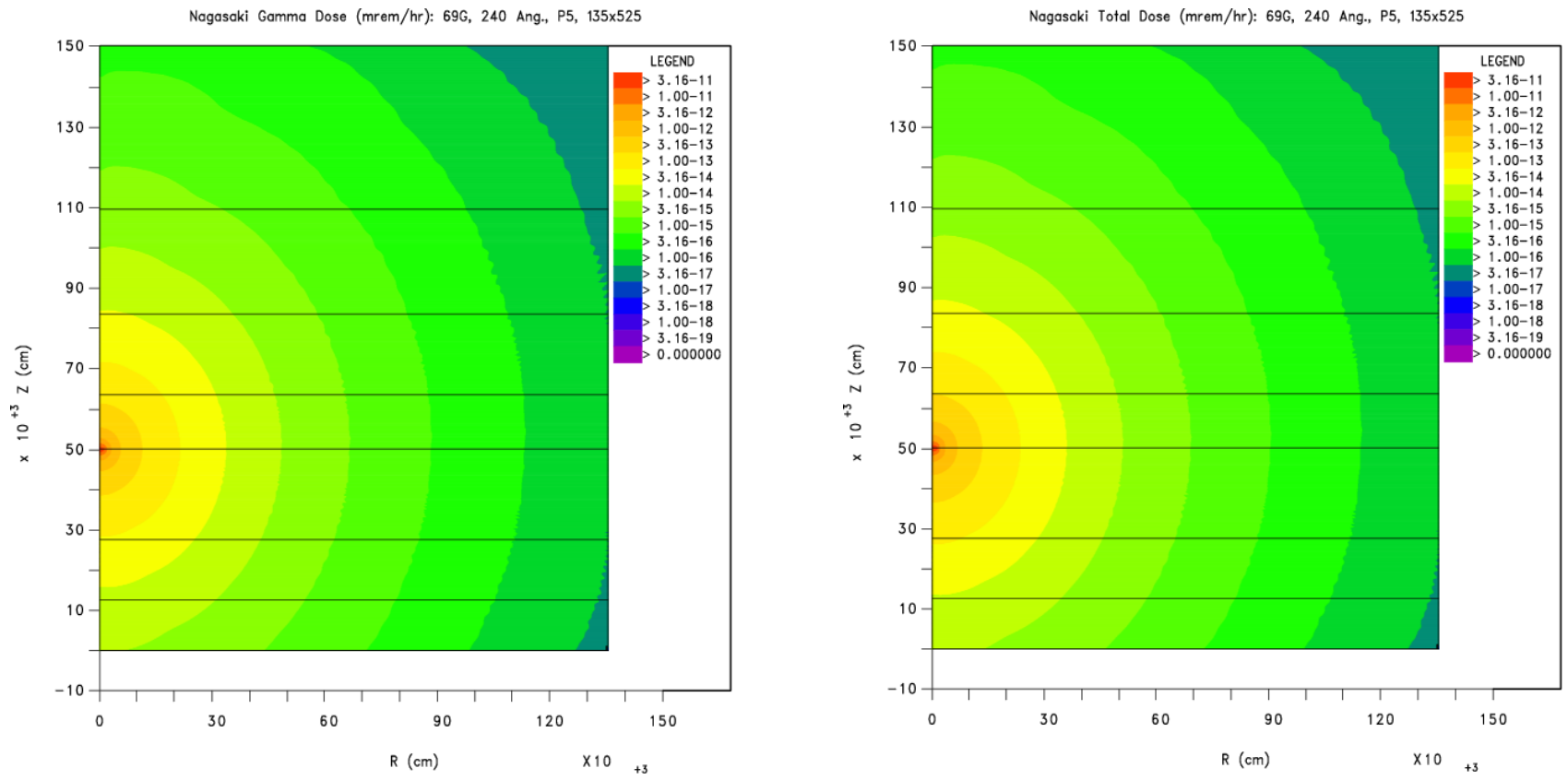

Figure 2. Total Uncollided Plus Collided Neutron, Gamma, and Total Dose Maps Over Entire Domain 

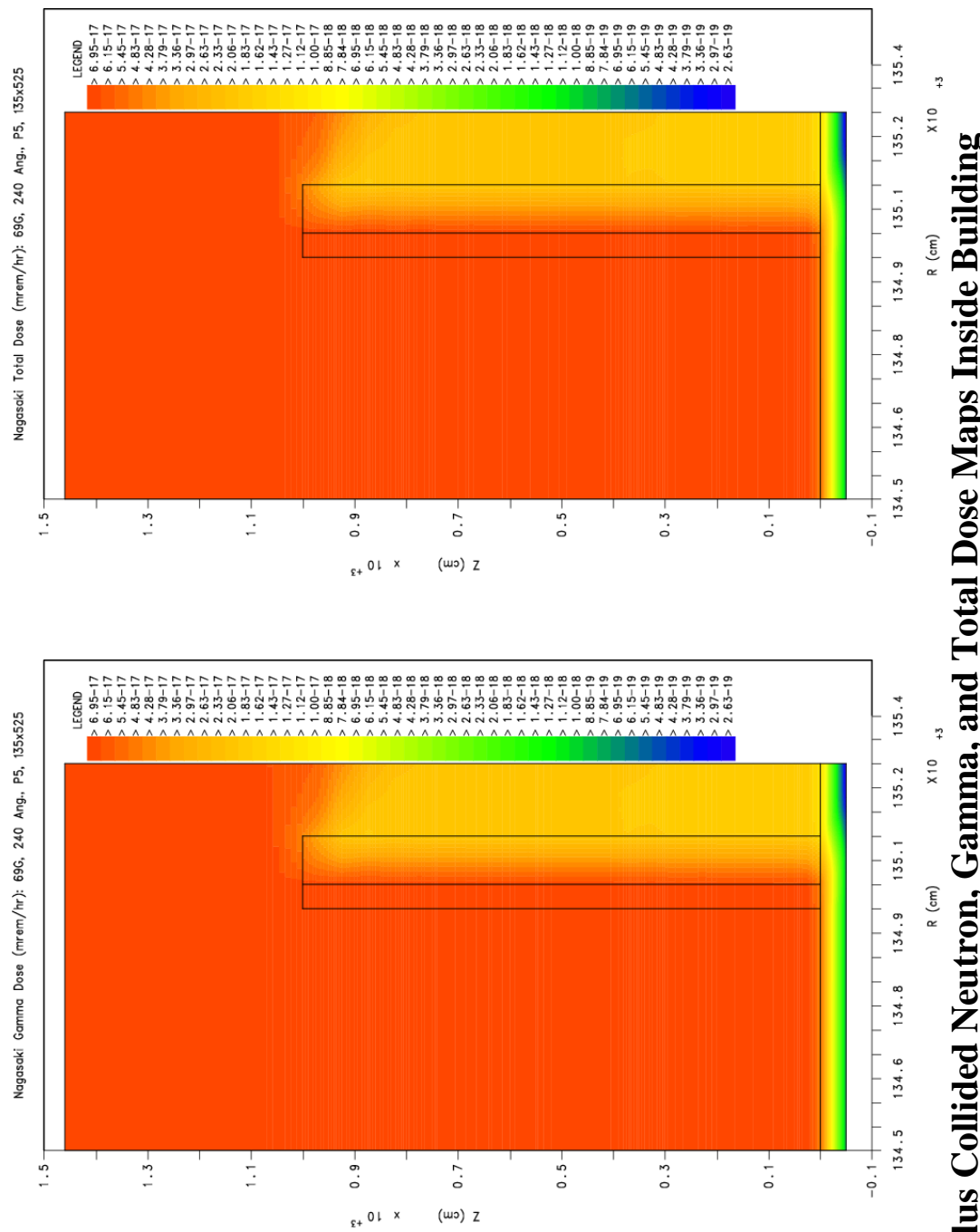

טֶ.

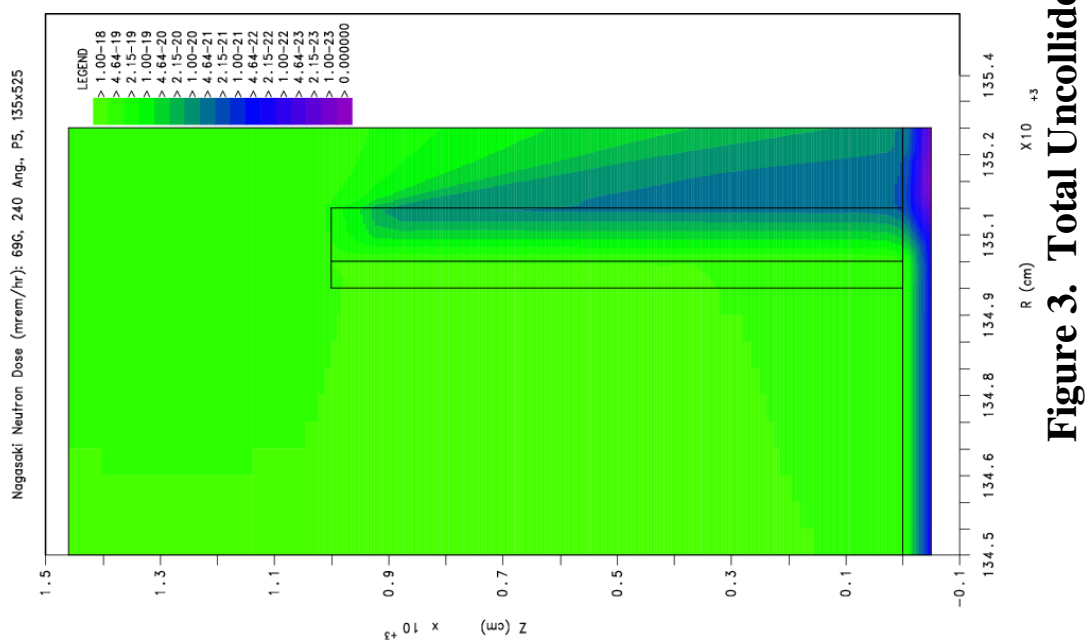




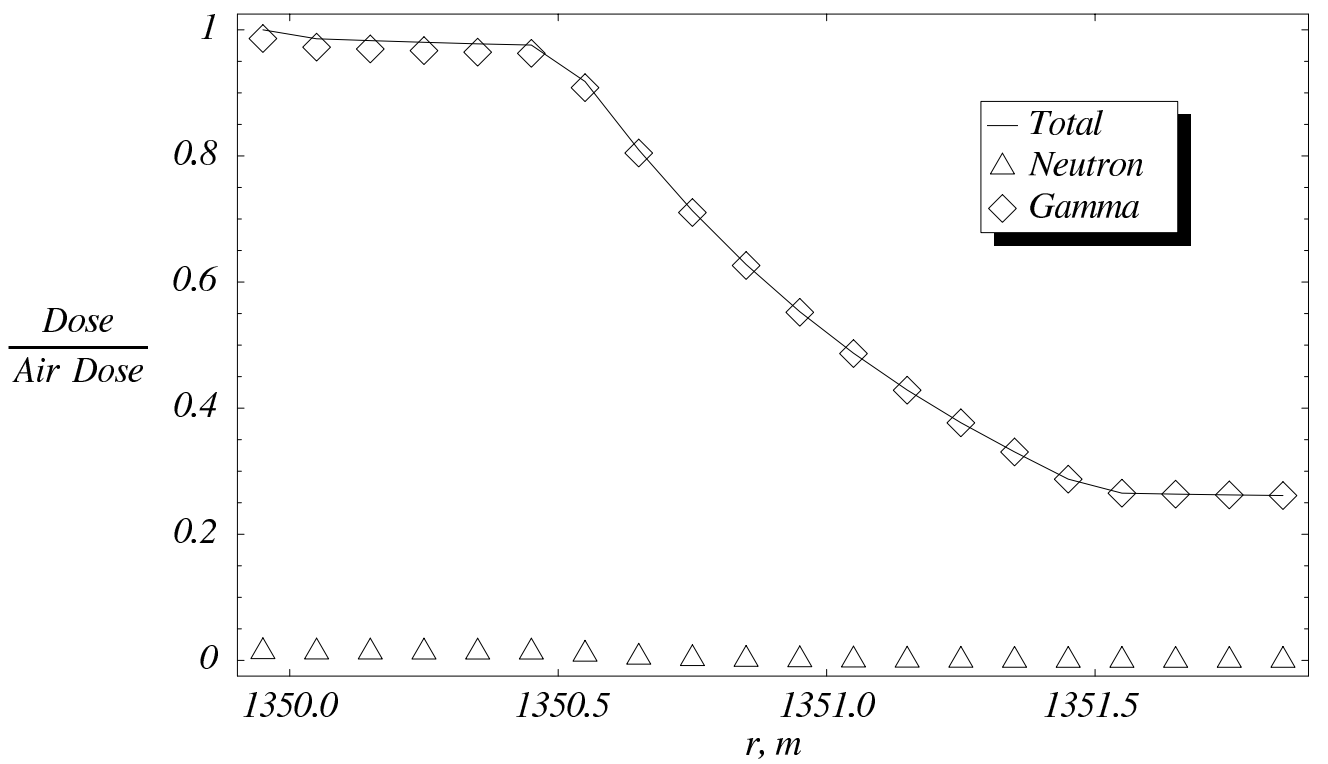

Figure 4. Relative Dose Inside Factory Building With Respect to the Dose Immediately Outside the Wall 


\section{REFERENCES}

1. William C. Roesch, Ed., Reassessment of Atomic Bomb Radiation Dosimetry in Hiroshima and Nagasaki, The Radiation Effects Research Foundation, Japan (1987).

2. W. A. Rhoades and R. L. Childs, "DORT: A Two-Dimensional Discrete Ordinates Transport Code," in A User's Manual for MASH 1.0 - A Monte Carlo Adjoint Shielding Code System, J. O. Johnson, Ed., ORNL/TM-11778, Oak Ridge National Laboratory (1992).

3. Yousry Y. Azmy, "The Three-Dimensional, Discrete Ordinates Neutral Particle Transport Code TORT: An Overview," OECD/NEA Mtg. on 3D Deterministic Radiation Transport Computer Programs, Features, Applications, and Perspectives, Paris, France, p. 17, OECD, Paris (1997).

4. D. B. Simpson, R. T. Santoro, Y. Y. Azmy, and J. V. Pace, Cross Sections and Source Spectrum for Nagasaki Dose Reconstruction for Risk Estimation, ORNL/TM-2001/16, Oak Ridge National Laboratory, to be published.

5. D. T. Ingersoll, R. W. Roussin, C. Y. Fu, J. E. White, DABL69: A Broad-Group Neutron/Photon Cross-Section Library for Defense Nuclear Applications, ORNL/TM10568, Oak Ridge National Laboratory (1989).

6. C. R. Weisbin, et. al., VITAMIN-E: An ENDF/B-V Multigroup Cross-Section Library for LMFBR Core and Shield, LWR Shield, Dosimetry, and Fusion Blanket Technology, ORNL/TM-5505, Oak Ridge National Laboratory (1979).

7. J. E. White, R. Q. Wright, D. T. Ingersoll, R. W. Roussin, N. M. Greene, and R. E. MacFarlane, "VITAMIN-B6: A Fine-Group Cross Section Library Based on ENDF/B-VI for Radiation Transport Applications," International Conference on Nuclear Data for Science and Technology, Gatlinburg, TN, p. 733, American Nuclear Society, La Grange Park, IL, (1994).

8. J. E. White, D. T. Ingersoll, R. Q. Wright, H. T. Hunter, C. O. Slater, N. M. Greene, R. E. MacFarlane, and R. W. Roussin, Production and Testing of the Revised VITAMIN-B6 Fine-Group and the BUGLE-96 Broad-Group Neutron/Photon Cross-Section Libraries Derived from ENDF/B-VI.3 Nuclear Data, ORNL-6795/R1, NUREG/CR-6214, Rev. 1 (April 2000).

9. R. L. Childs and J. V. Pace, III, "GRTUNCL: An Analytic First Collision Source Code," in A User's Manual for MASH 1.0 - A Monte Carlo Adjoint Shielding Code System, J. O. Johnson, Ed., ORNL/TM-11778, Oak Ridge National Laboratory (1992). 
10. W. A. Rhoades and M. B. Emmett, "GIP: A Group-Organized Cross Section Input Program," in A User's Manual for MASH 1.0 - A Monte Carlo Adjoint Shielding Code System, J. O. Johnson, Ed., ORNL/TM-11778, Oak Ridge National Laboratory (1992). 


\section{APPENDIX A \\ GROUP DOSE RATE DISTRIBUTION}





\section{APPENDIX A}

\section{GROUP DOSE RATE DISTRIBUTION}

The figures in this Appendix depict color coded maps of the dose rate by group over the entire problem domain. The dose rates are based on the total, i.e. uncollided plus fully collided, particle flux. Group 1 dose is not plotted because the source in this group is zero, hence so is the dose in this group. The computational model is described in Section 2. The dose maps from neutrons are shown in Figures A1-A8, while the dose maps from gammas are shown in Figures A9-A12. Note that the color code scale is not fixed across groups in order to provide adequate detail of the dose distribution in each case. 

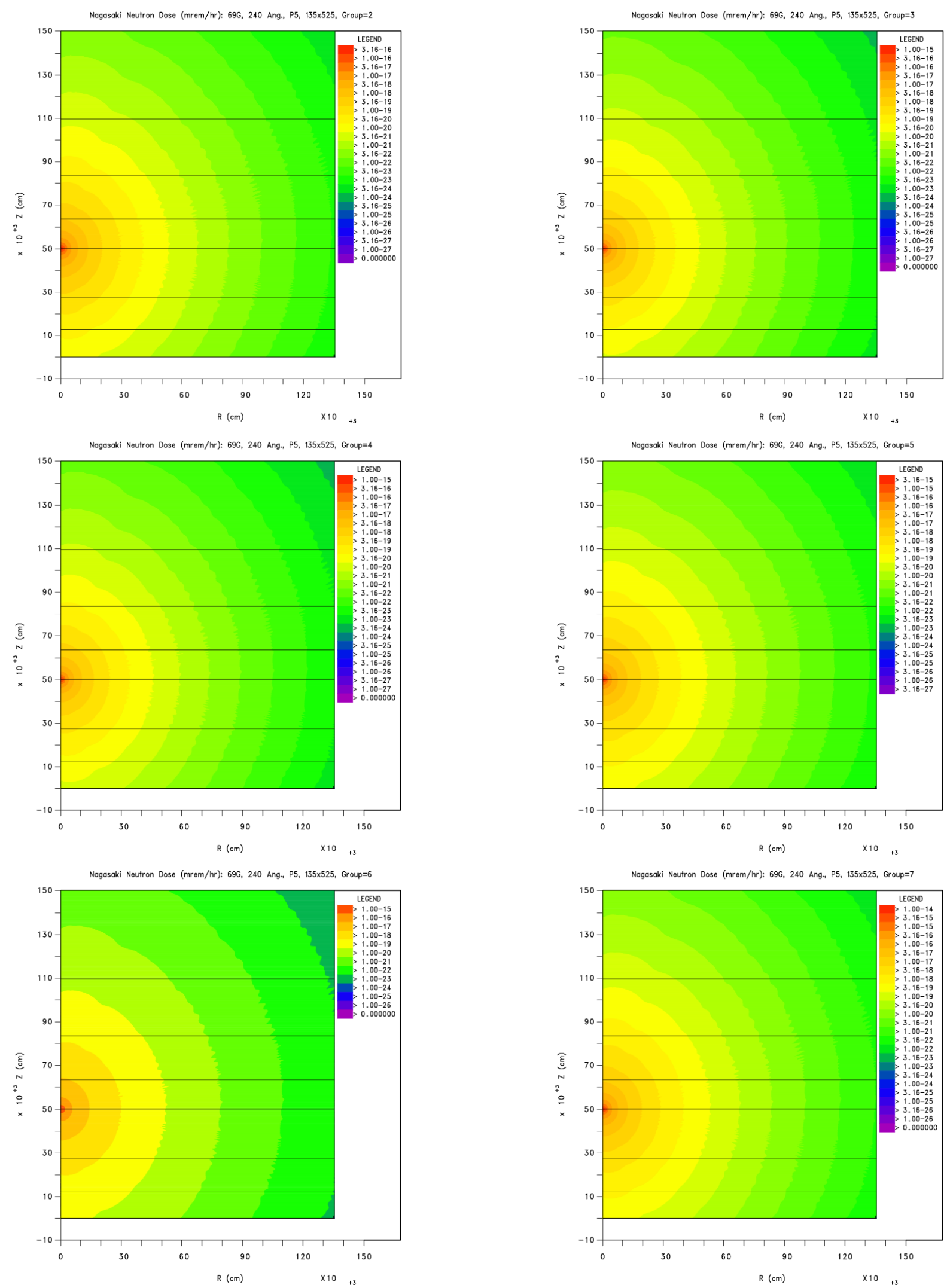

Figure A1. Neutron Uncollided Plus Collided Dose Maps for Energy Groups 2-7 

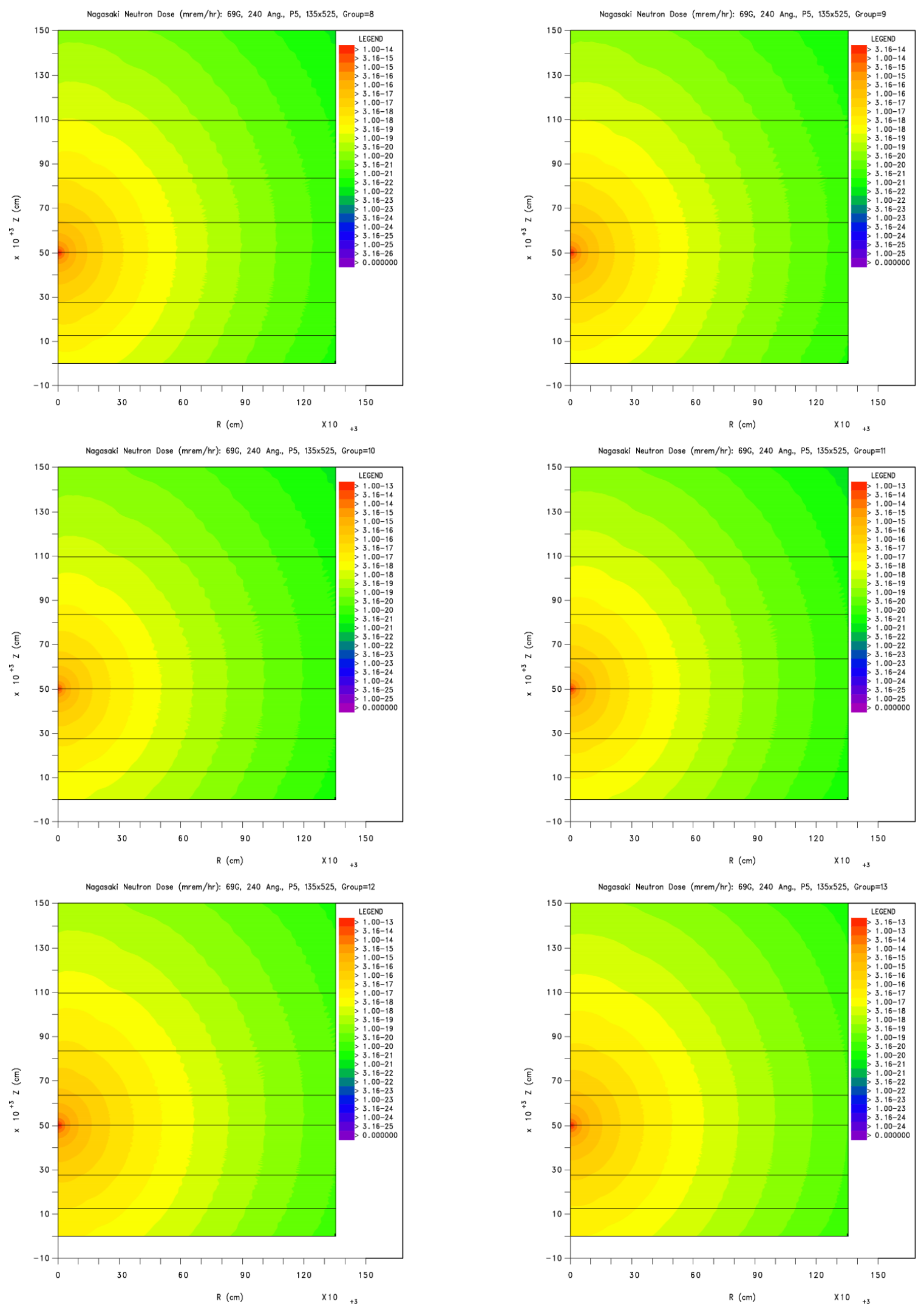

Figure A2. Neutron Uncollided Plus Collided Dose Maps for Energy Groups 8-13 

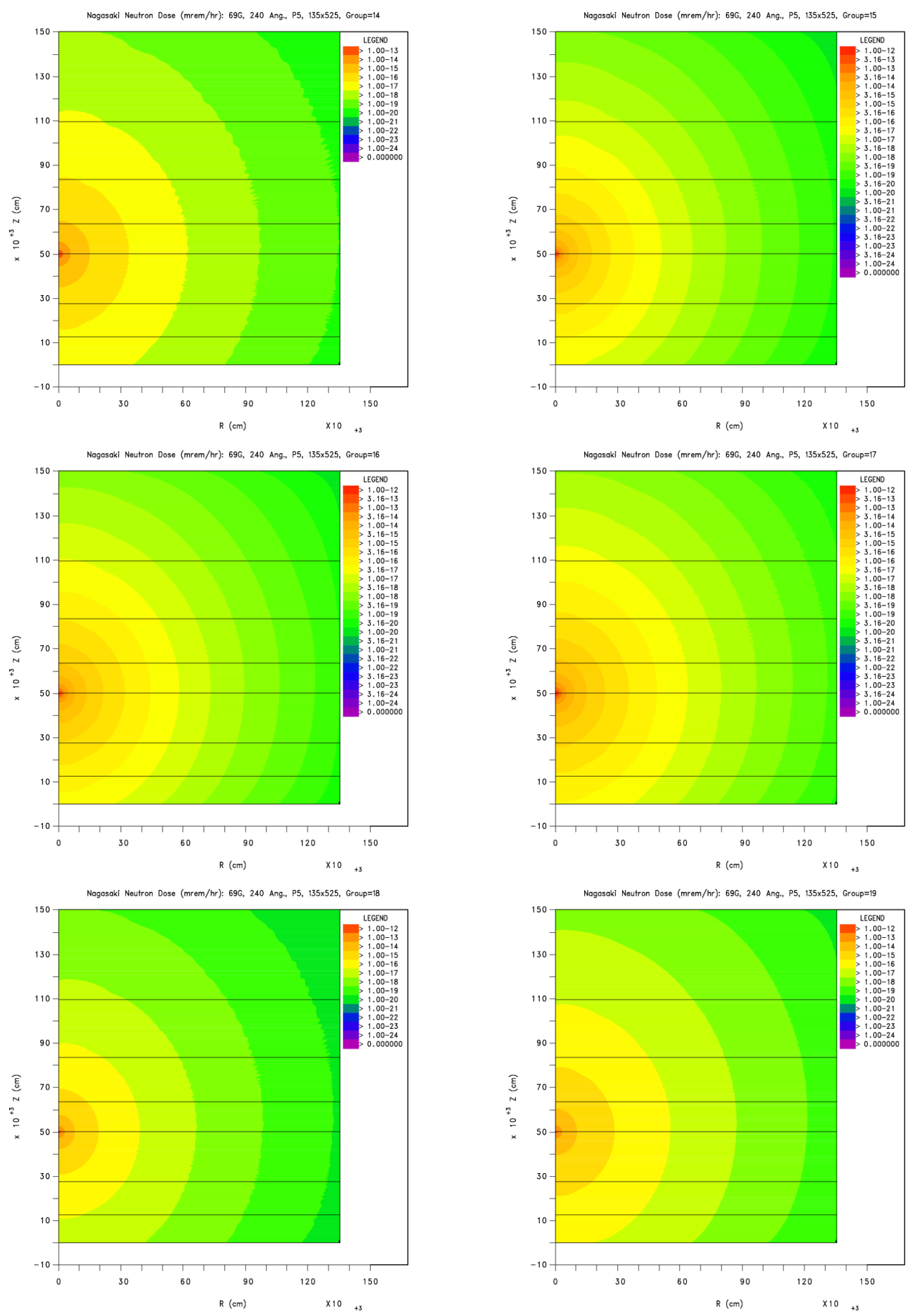

Figure A3. Neutron Uncollided Plus Collided Dose Maps for Energy Groups 14-19 

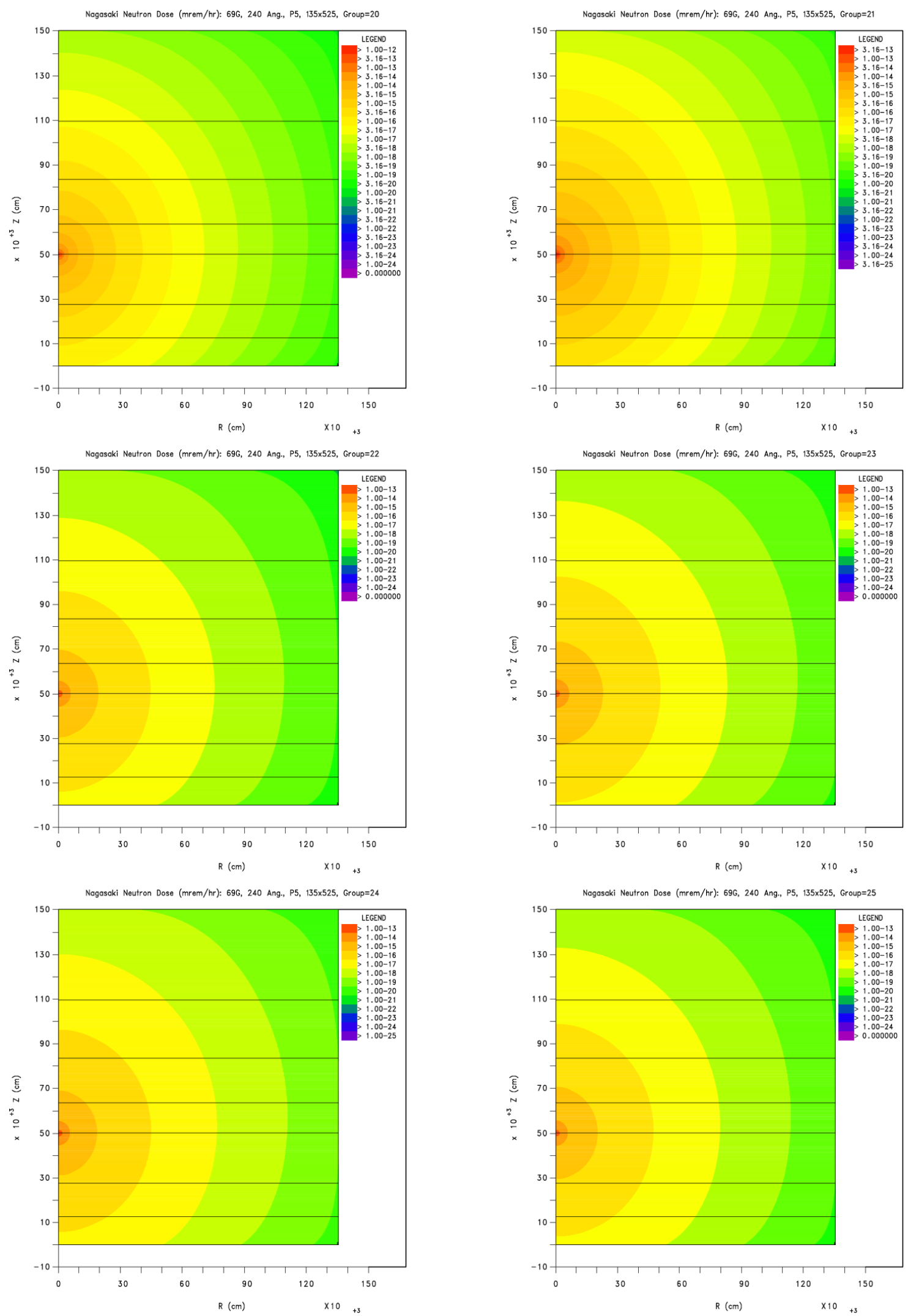

Figure A4. Neutron Uncollided Plus Collided Dose Maps for Energy Groups 20-25 

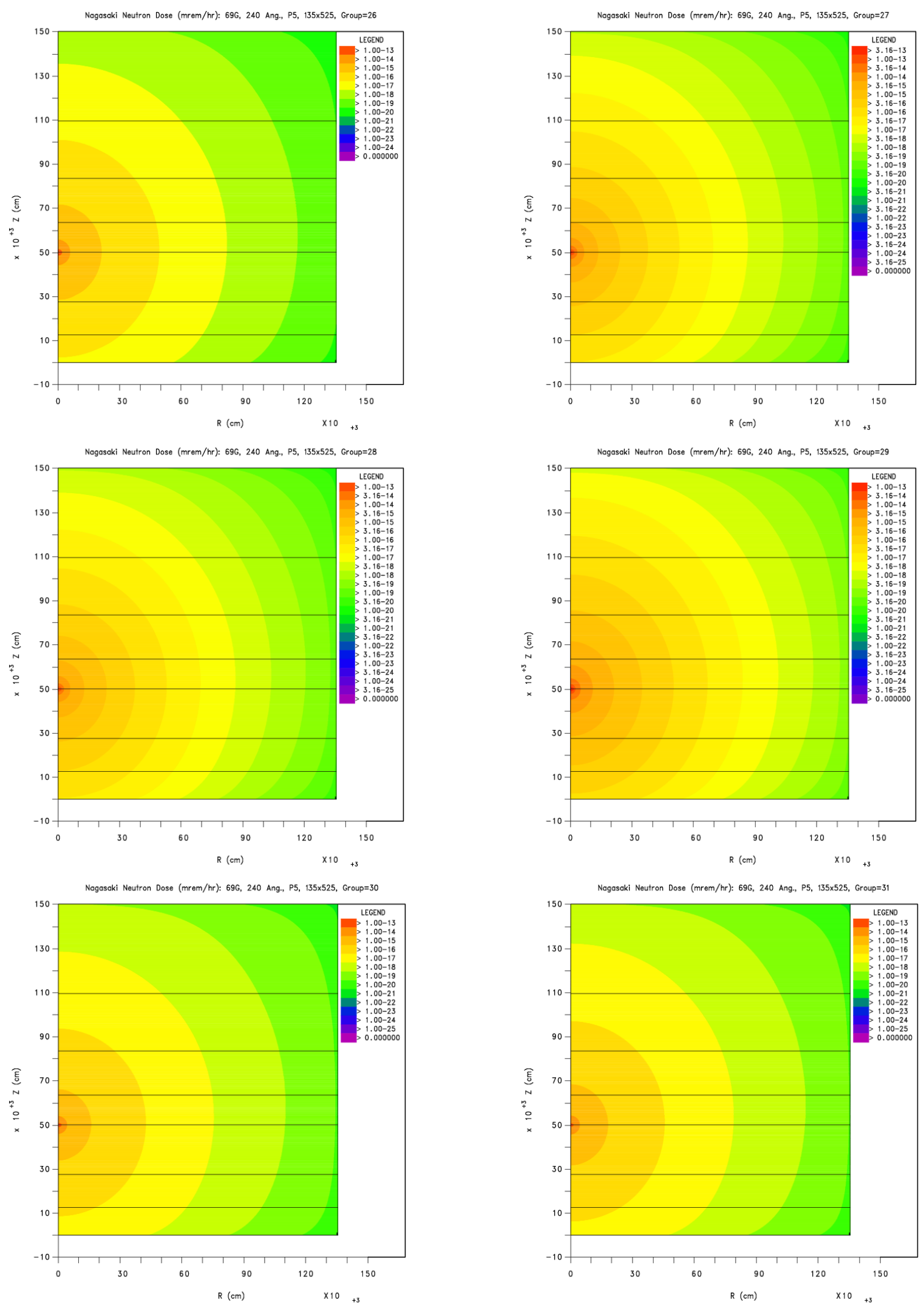

Figure A5. Neutron Uncollided Plus Collided Dose Maps for Energy Groups 26-31 

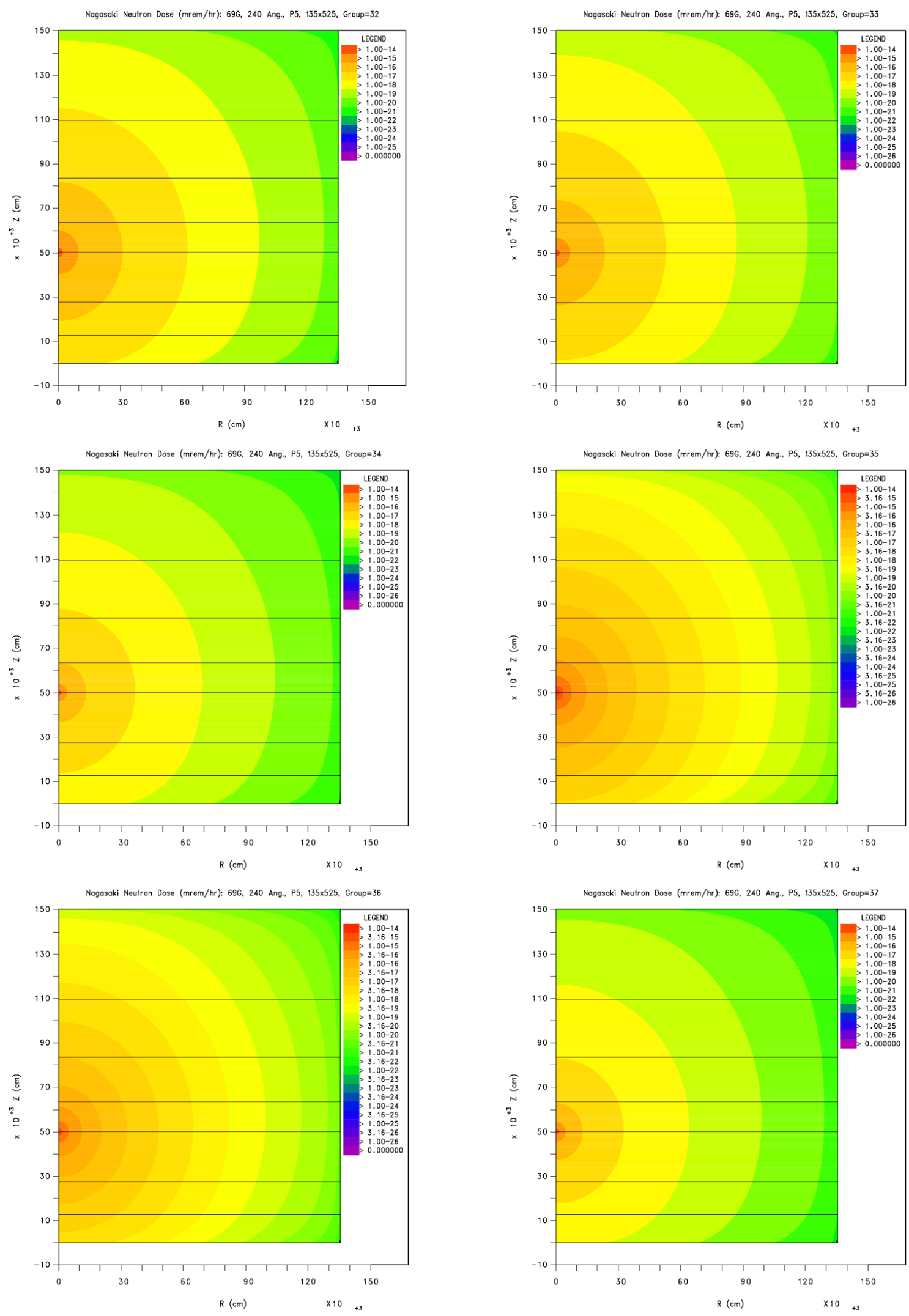

Figure A6. Neutron Uncollided Plus Collided Dose Maps for Energy Groups 32-37 

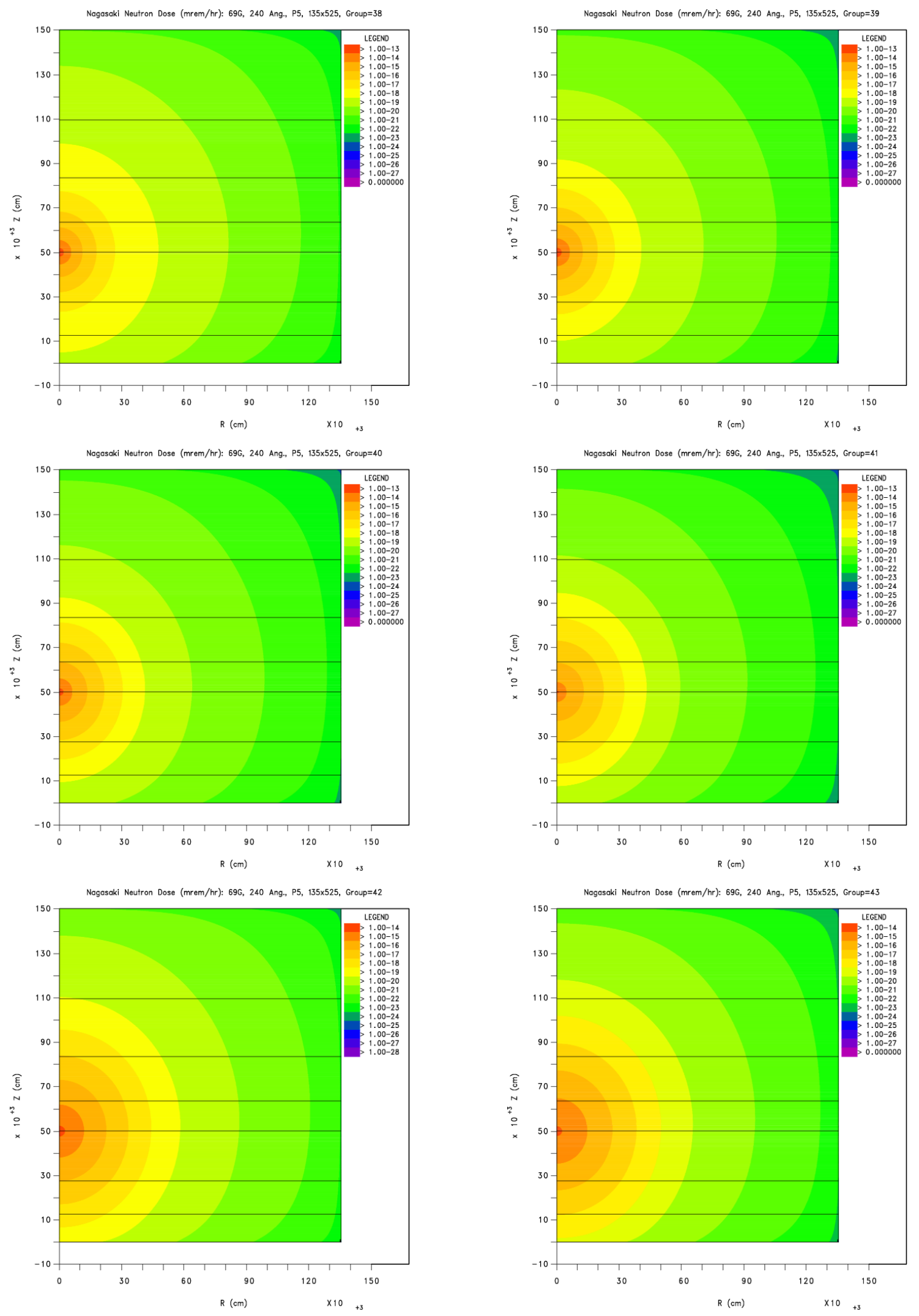

Figure A7. Neutron Uncollided Plus Collided Dose Maps for Energy Groups 38-43 

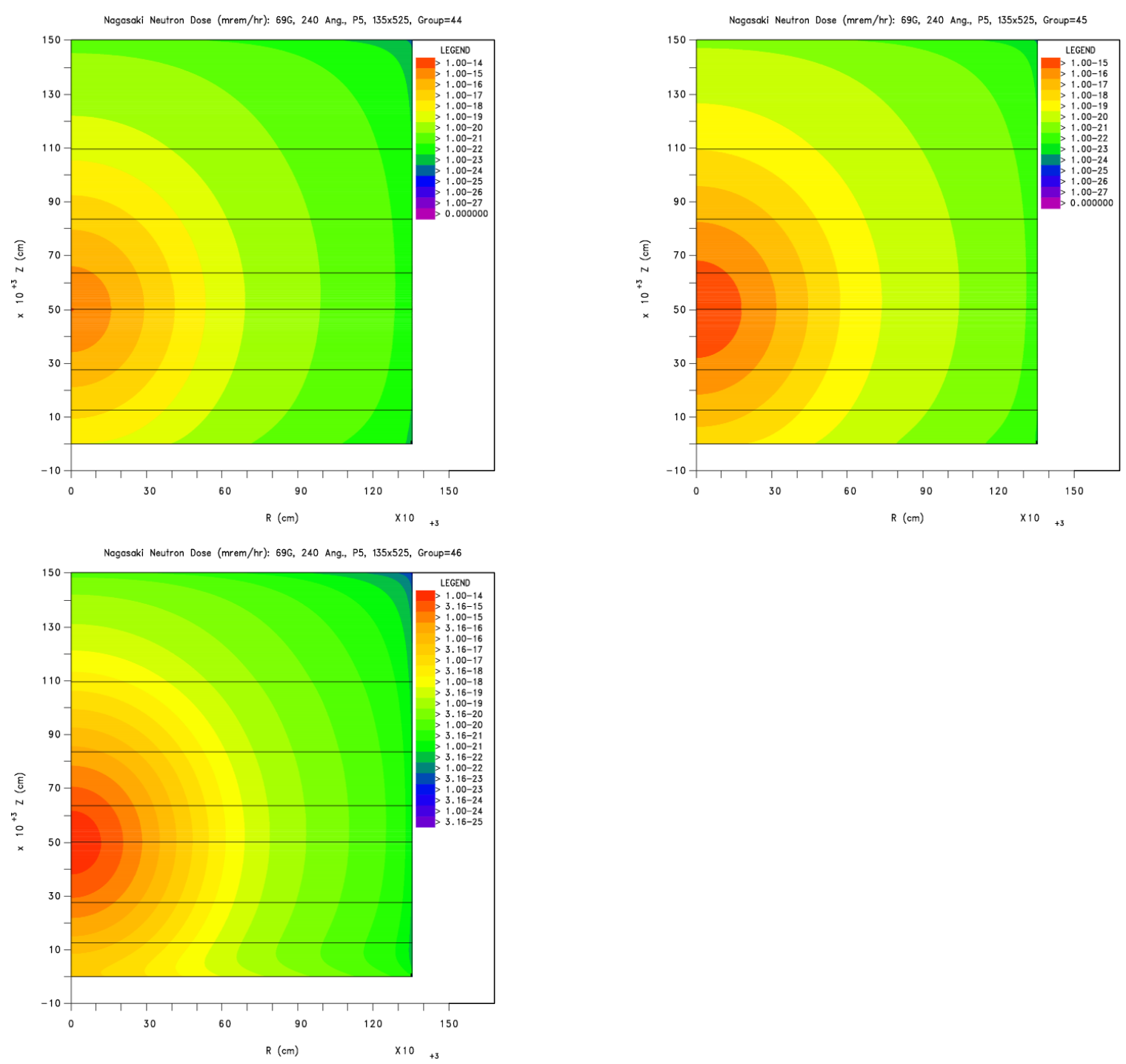

Figure A8. Neutron Uncollided Plus Collided Dose Maps for Energy Groups 44-46 

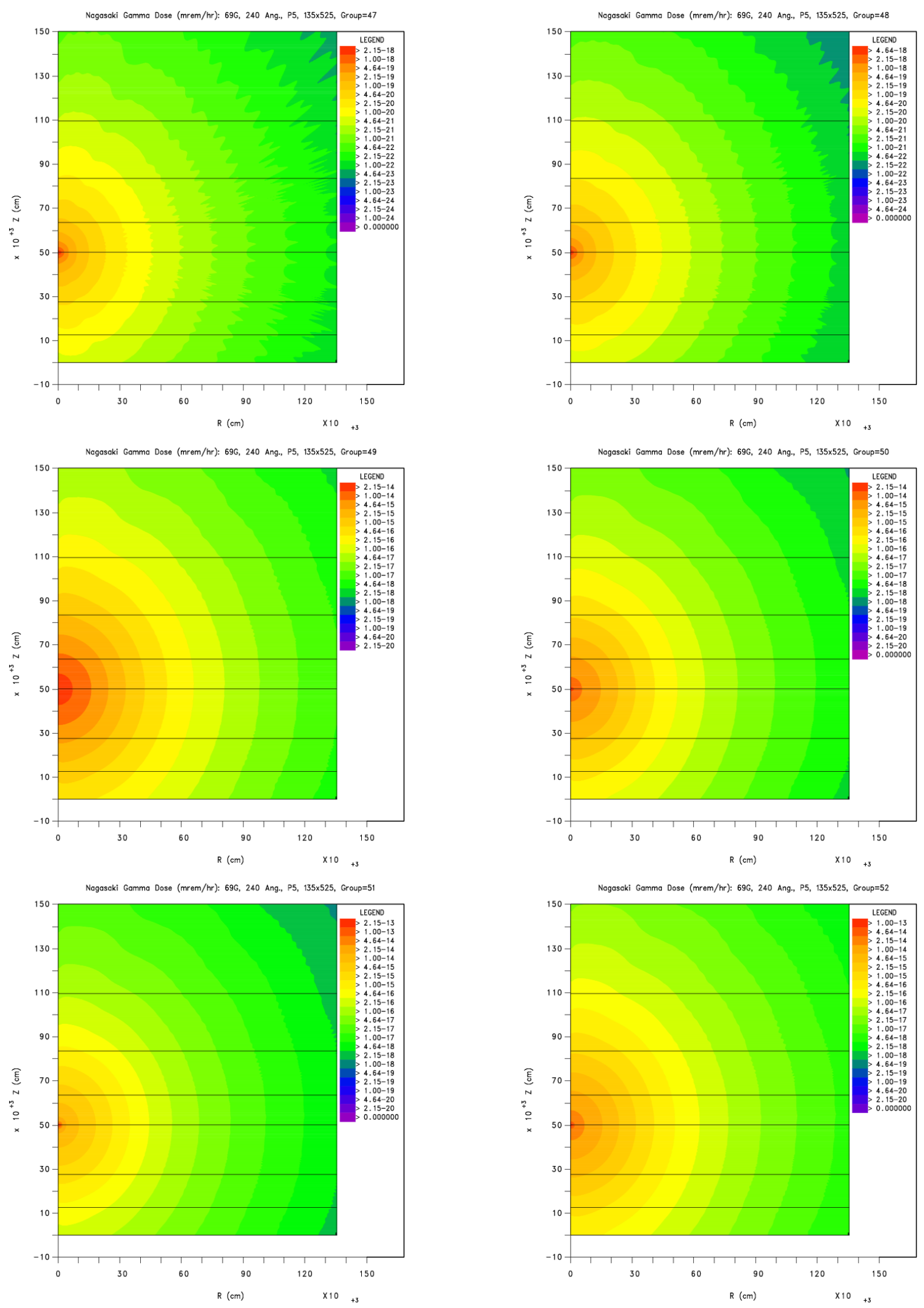

Figure A9. Gamma Uncollided Plus Collided Dose Maps for Energy Groups 47-52 

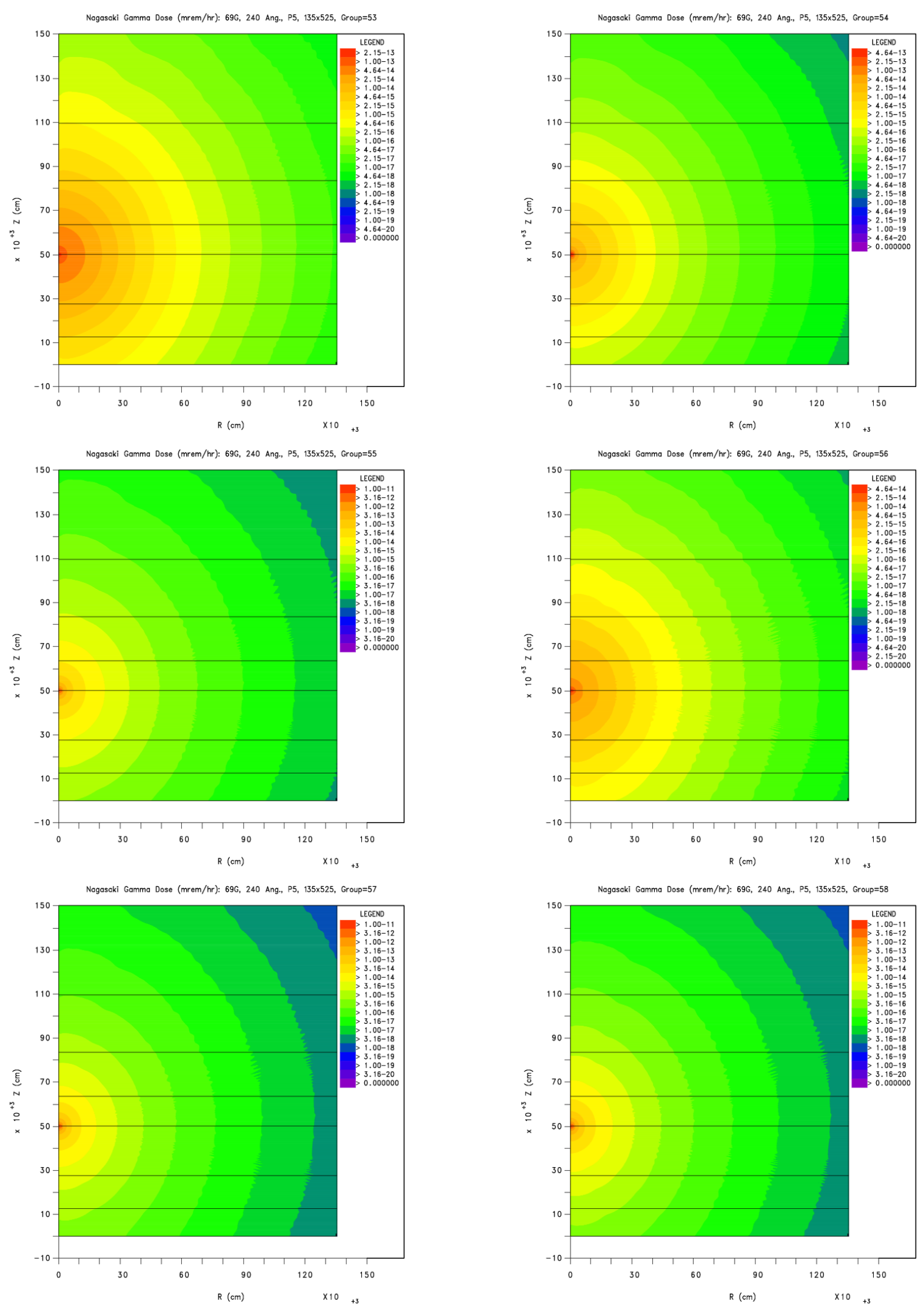

Figure A10. Gamma Uncollided Plus Collided Dose Maps for Energy Groups 53-58 

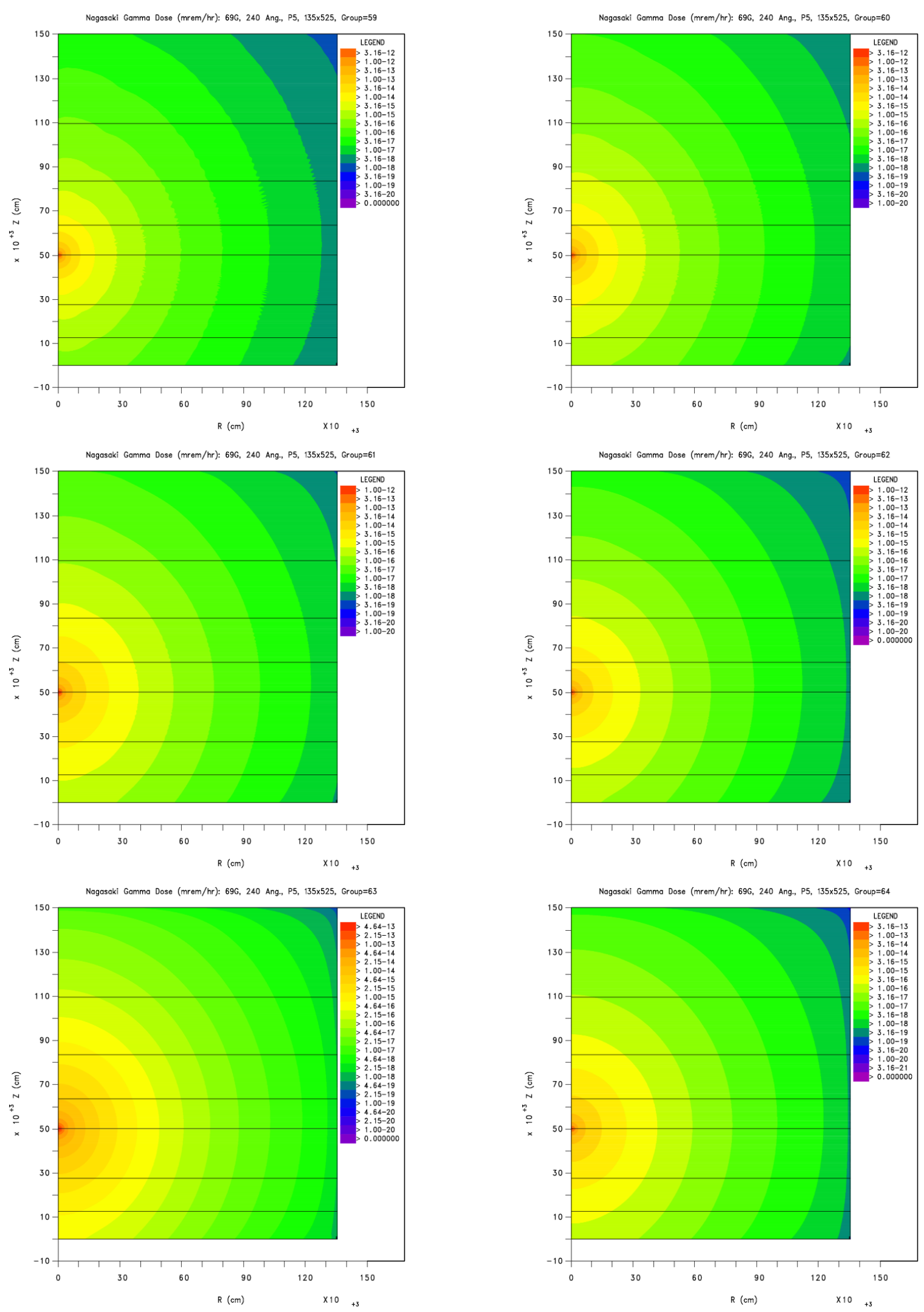

Figure A11. Gamma Uncollided Plus Collided Dose Maps for Energy Groups 59-64 

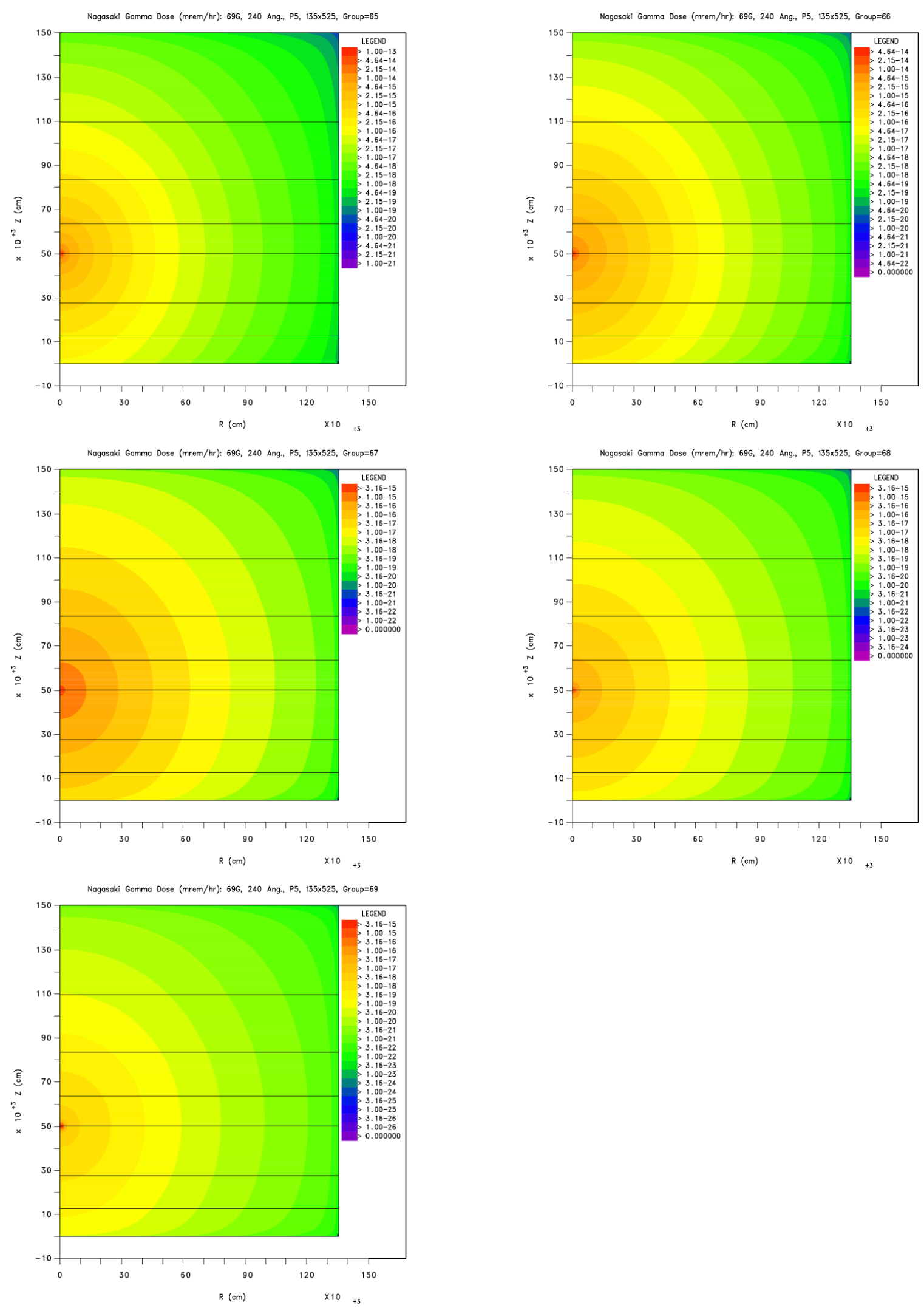

Figure A12. Gamma Uncollided Plus Collided Dose Maps for Energy Groups 65-69 



\section{INTERNAL DISTRIBUTION}

$\begin{aligned} \text { 1-2. } & \text { Y. Y. Azmy } \\ \text { 3. } & \text { J. M. Barnes } \\ \text { 4. } & \text { D. T. Ingersoll } \\ \text { 5. } & \text { R. A. Lillie } \\ \text { 6. } & \text { M. A. Kuliasha } \\ \text { 7-8. } & \text { J. V. Pace III }\end{aligned}$

\author{
9-10. R. T. Santoro \\ 11-12. D. B. Simpson \\ 13. Central Research Library \\ 14. Laboratory Records-RC \\ 15. Laboratory Records (for \\ submission to OSTI)
}

\section{EXTERNAL DISTRIBUTION}

16. Dr. Robert F. Christy, 1230 Arden Road, Pasadena, CA 91106

17. Dr. Harry M. Cullings, Department of Statistics, Radiation Effects Research Foundation, 5-2 Hijiyama Park, Minami-ku, Hiroshima-shi, 732-0815 Japan

18. Dr. Stephen D. Egbert, SAIC, 10260 Campus Pointe Drive, MSX2, San Diego, CA 92121-1578

19. Dr. Alexandra R. Heath, Diagnostics Applications Group Leader, Los Alamos National Laboratory, MS F663, , Los Alamos, NM 87545

20. Mr. Dean C. Kaul, SAIC, 10260 Campus Point Drive, MSX2, San Diego, CA 92121-1578

21. Dr. George D. Kerr, Kerr Consulting, P.O. Box 12052, Knoxville, TN 37912-0052

22. Dr. Tore Straume, University of Utah, Radiobiology Division, 729 Arapeen Drive, Suite 2334, Salt Lake City, UT 84108

23. Dr. David G. Thomassen, Office of Biological and Environmental Research, U.S. Department of Energy, ER-72, 19901 Germantown Road, Germantown, MD 20874-1290

24. Dr. Joseph Weiss, Office of Health Studies, U.S. Dept. of Energy, EH-6/270CC, 19901 Germantown Road, Germantown, MD 20874-1290

25. Dr. Paul P. Whalen, Los Alamos National Laboratory, MS D413 Los Alamos, NM 87545

26. Dr. Robert W. Young, 946 Torrey Pine Drive, Winter Springs, FL 32708-4346 